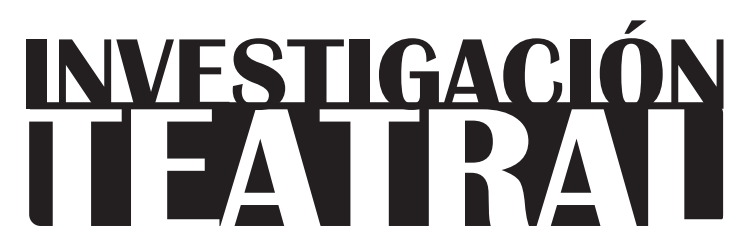

Revista de artes escénicas y performatividad

Vol. 12, Núm. 19

abril-septiembre 2021

Segunda época

ISSN impreso: 1665-8728

ISSN electrónico: 2594-0953

Universidad Veracruzana

Reseña de libro

\title{
Teatro de ayer y hoy a escena, de José Romera Castillo
}

\author{
Raquel Graciela Gutiérrez Estupiñán*
}

\footnotetext{
* Universidad Autónoma de Puebla, México. e-mail: raquelgmx@yahoo.com
}

Recibido: 14 de diciembre de 2020 Aceptado: 17 de diciembre de 2020

Doi: $10.25009 /$ it.v12i19.2664 


\title{
Teatro de ayer y hoy a escena, de José Romera Castillo
}

\author{
Romera Castillo, José. Teatro de ayer y hoy a escena. Madrid: Verbum, 2020, \\ 439 pp., ISBN 9788413372501
}

$\mathrm{N}$

o es tarea sencilla reseñar un libro que es, en sí mismo, una extensa reseña de la diversidad de asuntos relacionados con el teatro español en la actualidad (ver Imagen 1). A lo largo de más de 400 páginas y 18 capítulos, José Romera Castillo nos conduce desde la superficie de la actividad teatral hasta recovecos que, sin su guía, permanecerían insospechados para muchos de nosotros. ${ }^{1}$ El contenido de este libro se relaciona con los estudios teatrales desde el punto de vista de lo textual y de lo espectacular. Presentaremos en seguida una serie de anotaciones sobre los puntos que aborda cada uno de los capítulos.

El teatro clásico, pieza importante del patrimonio cultural, ha sido objeto de abundantes puestas en escena, así como de estudios tanto de texto y como de espectáculo. Entre los autores más estudiados y representados están Calderón de la Barca, Lope de Vega, Francisco de Rojas Zorrilla, Agustín Moreto y Tirso de Molina (Capítulo 1).

La conmemoración del cuarto centenario de los fallecimientos de Cervantes y de Shakespeare dio lugar, en 2016, a una exposición en la Biblioteca Nacional de Madrid, actos culturales diversos, estudios biográficos y, especialmente, estudios sobre el teatro cervantino, al lado de puestas en escena de obras de ambos autores. De Cervantes se hicieron

1 A manera de prolegómenos, José Romera Castillo da cuenta de las fructíferas líneas de trabajo surgidas a iniciativa suya. Numerosas son las contribuciones de diversos centros de investigación sobre literatura y teatro -entre los cuales destaca el Seminario de Literatura, Teatro y Nuevas Tecnologías (SELiTEN@T)dentro del hispanismo internacional. A lo largo de cada capítulo se consignan los seminarios organizados, así como publicaciones y tesis dirigidas por el autor de esta obra. 
INVESTIGACIÓNTEATRAL

Revista de artes escénicas y performatividad

Vol. 12, Núm. 19

abril-septiembre 2021
Teatro de ayer y hoy a escena,

de José Romera Castillo

Raquel Graciela Gutiérrez Estupiñán

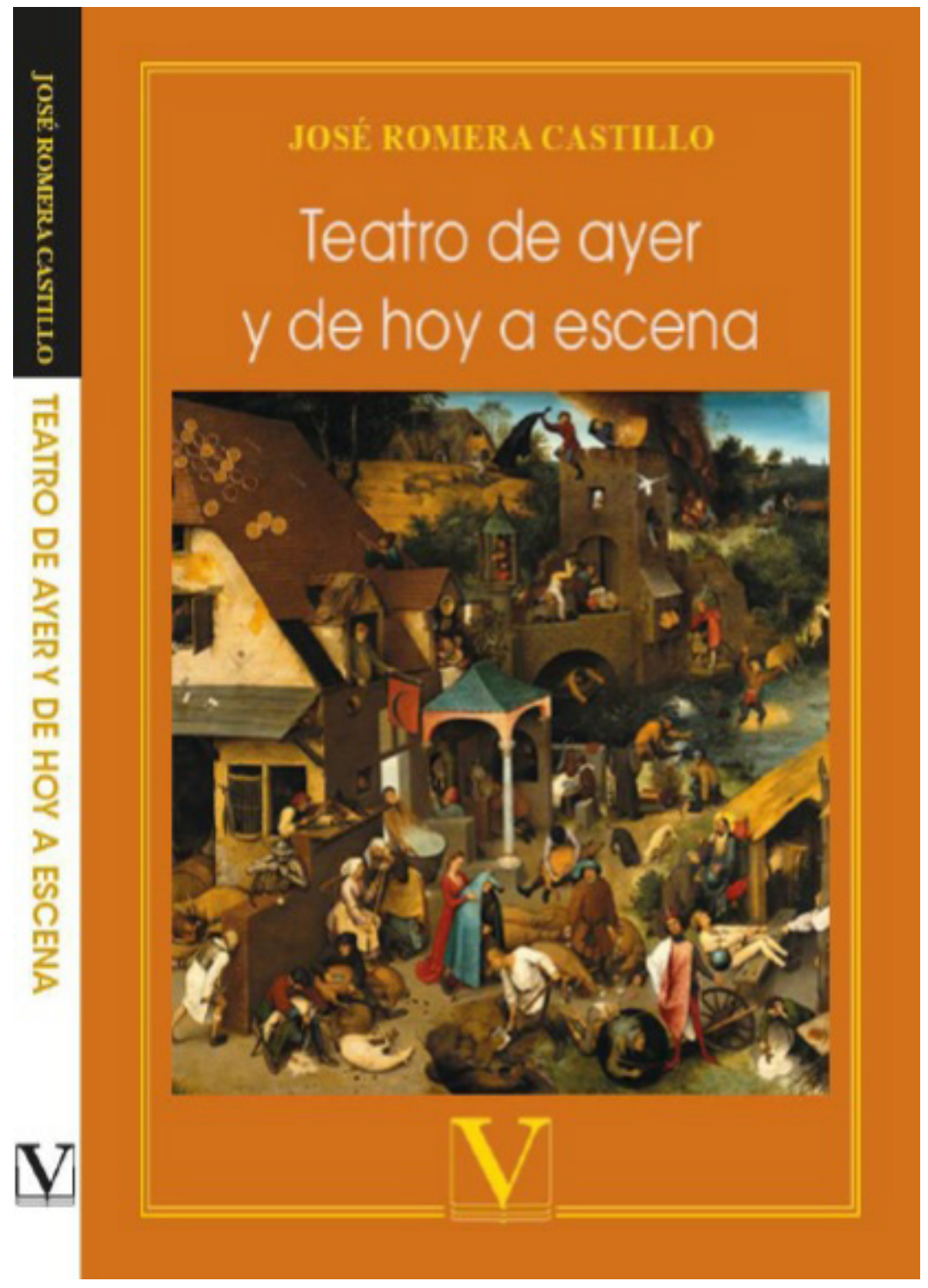

Imagen 1. Portada del libro Teatro de ayer y hoy a escena, de José Romera Castillo.

modernizaciones y adaptaciones del Quijote. José Romera Castillo lamenta la ausencia de puestas en escena de obras de Cervantes, y que en lugar de ello se haya recurrido a "meras adaptaciones o conglomerados con visiones poco ortodoxas" (89). Asimismo, hubo representaciones y adaptaciones de varias de las Novelas Ejemplares, así como del Quijote en clave femenina (Capítulo 2).

En el Capítulo 3 se realiza un recuento de obras (incluida la presencia de Dumas en el teatro español), óperas y zarzuelas. Muchos trabajos son de la autoría de Romera Castillo, 
ya se trate de recopilaciones, organización de seminarios, dirección de tesis, publicaciones, estudios de carteleras o investigaciones sobre la vida escénica, en Madrid y en otras provincias. El Capítulo 4 está dedicado a dos figuras históricas en los escenarios: Fernán González (c. 901-970), tratado en obras de Lope de Vega, Zorrilla y Larra, entre otros, y Guzmán el Bueno (1256-1309), fundador de la casa de Medinaceli. Por su parte, el Capítulo 5 aborda la figura del trovador, en la obra homónima de Antonio García Gutiérrez, que fue objeto de una ópera de Verdi: Il Trovatore (1853). En cuanto a las puestas en escena, se consignan las realizadas en Madrid, París, Barcelona y muchas otras ciudades, a mediados del siglo xIX. Señala Romera Castillo que "el teatro, en su acepción más plena, al ser representado, no es solo un fenómeno artístico, sino que también -y además- se convierte en un hecho cultural y social de primera instancia" (150). Esta idea es primordial a lo largo de todo el libro.

El capítulo sobre el teatro de los siglos XX y XxI (Capítulo 6) inicia con una exposición de estudios realizados en el SELITEN@T. Se nota la presencia de temas que no habían aparecido hasta ahora, a saber: la dramaturgia de mujeres y las relaciones entre teatro e internet. Al teatro en los inicios del siglo XXI se dedica el Capítulo 7. Romera Castillo expresa su objetivo de realizar unas breves calas en los cuantiosos trabajos realizados en torno a diversos aspectos del teatro actual, una de las artes vivas, que exige la colaboración del espectador. Se ofrece un listado de teatros activos en la zona metropolitana y se señala la diversa calidad de los espectáculos. El estudio de la cartelera madrileña, en abril de 2013, pone de relieve la inclusión obras de autores como Lope de Vega, Tirso de Molina, y Shakespeare.

En cuanto a dramaturgias femeninas, Romera Castillo consigna una escasa presencia en el mes considerado (solo dos muestras). El discurso histórico interviene en el teatro, en obras sobre asuntos históricos y políticos. También hay muestras de teatro biográfico, a través de la reposición de La monja Alférez (de 1986) y la puesta en escena de dos obras sobre García Lorca. Otros elementos señalados son el humor, el erotismo, el teatro breve y los musicales, estos últimos atribuidos a una colonización ideológico-cultural proveniente de los países anglosajones. Dentro de lo multimediático, Romera Castillo se refiere al trasvase del teatro al cine y a las relaciones entre el teatro y la televisión.

El Capítulo 8 está consagrado a algunas modalidades del espacio en el teatro español. De nuevo, el autor realiza una serie de calas en el amplio tema del espacio en el teatro. Consigna referencias bibliográficas correspondientes al siglo XXI y se ocupa también de la sonoturgia, es decir de los signos acústicos, sobre todo musicales, que forman parte de los espectáculos teatrales. Algunos proyectos utilizan el plató televisivo como espacio escénico, o bien el internet. Romera Castillo nos recuerda que el "teatro a domicilio" tiene una larga historia: en los palacios reales, en las casas de los nobles, y luego en las 
calles. Da el ejemplo de Miami, donde un teatro alternativo lleva espectáculos a casas, oficinas, bares, cafés, con la finalidad de acercarse al público. El Capítulo 9 hace notar que, puesto que el teatro actual ha entrado de lleno en los circuitos de investigación y es objeto de estudio en los ámbitos universitarios, los premios son un elemento que debe tomarse en cuenta. ${ }^{2}$

Acerca del teatro como hilo de unión entre España y Europa, el Capítulo 10 comienza con una reflexión sobre las raíces comunes entre ambos, y se refiere a la diversidad de producciones teatrales en estos ámbitos. La Compañía Nacional de Teatro Clásico destaca por su labor de "recuperar, preservar, difundir y dar a conocer el teatro áureo español" (Romera 255), a la vez que mantiene relaciones con América y con Europa.

El Capítulo 11 aborda las técnicas metateatrales. A guisa de apertura, Romera Castillo ofrece un recuento bibliográfico sobre el término "metateatro", en obras entre 1963 y 2006, para preguntarse en seguida sobre el caso del teatro español y señalar que dará algunas muestras de ensayos críticos monográficos acerca del tema, en revistas de distintos lugares de España. El metateatro, "un rasgo muy significativo del teatro en la actualidad" (283), ofrece diversas facetas y ha sido objeto de numerosos estudios. En seguida, Romera Castillo ofrece un "viaje entretenido" por espectáculos referidos al teatro dentro del teatro. Se menciona asimismo la presencia en escena de los autores de los textos, como la de Vargas Llosa en Los cuentos de la peste, en 2015. En el rubro del teatro biográfico se alude a tres piezas dedicadas a Emilia Pardo Bazán, María Teresa León y Eva Forest.

Las dramaturgias femeninas en los inicios del siglo xxI constituyen, al lado del momento brillante por el que está pasando el teatro español, uno de sus rasgos sobresalientes, por el empuje de la dramaturgia escrita por mujeres, lo cual habla de su visibilidad tanto en el terreno de la autoría como en el de la actuación. El SELITEN@T, atento a este hecho, participa en proyectos con Francia y Alemania, además de que organiza seminarios internacionales y temáticos. ${ }^{3}$ Los aspectos que se estudian en la actualidad son el erotismo, teatro e internet, teatro y música, teatro y marginalismo, teatro y filosofía, entre otros. El conjunto de estas actividades da testimonio de que las mujeres

2 Romera Castillo menciona los de la Fundación GAR, los Max de las Artes Escénicas, dirigidos a diversos sectores: puestas en escena de autores clásicos (Calderón de la Barca, por ejemplo) o clásicos intermedios (García Lorca). Cabe aclarar que también se representan obras de autores como Brecht (Madre Coraje) y Shakespeare (243).

3 Destacan dos antologías derivadas de estos eventos: Dramaturgas españolas en la escena actual (García-Pascual, Raquel, editora. Madrid: Castalia, 2011), y Dramaturgas del siglo XXI (Gutiérrez Carbajo, Francisco, editor. Madrid: Cátedra, 2014). 
han llegado a ocupar el espacio teatral "buscando la paridad con sus congéneres, los hombres" (Romera 307). Fuera del ámbito europeo, se han dedicado estudios a la obra de dramaturgas argentinas y latinoamericanas; muestra de este interés es el proyecto Dramaturgae (Capítulo 13).

Los espectáculos teatrales formaron parte de los eventos organizados con motivo del World Pride Madrid 2017 (Capítulo 14). Entre ellos destaca el festival cultural Mado (Madrid Orgullo), en cuyo programa figuraron obras teatrales que abordaban temas como la identidad de género, el poder del amor para eliminar barreras y las relaciones entre sexo, raza e ideología. Se considera que el teatro es "buen espejo de lo que está sucediendo a su alrededor" (335) y contribuye a hacer visibles las opciones del colectivo LGTBIQ.

Las manifestaciones del erotismo en el teatro no han recibido la atención pormenorizada que merecen, escribe el autor en el capítulo siguiente (el 15), dedicado a este tema. Al respecto, el SELITEN@T ha organizado seminarios internacionales, ${ }^{4}$ con lo cual este grupo de estudios se erige como pionero en el conocimiento de la presencia de lo erótico en lo teatral. Romera Castillo, quien ha dedicado numerosas publicaciones en torno a la obra de Antonio Gala, explora, en el Capítulo 16, la interacción entre el lenguaje musical, el poético y el teatral. Aborda aspectos como la musicalidad en la poesía de Gala, que se aprecia en grabaciones de algunos de sus libros y en la musicalización de sus textos por parte de varios artistas, como Montserrat Caballé. Continuando con el tema de la música en el teatro, el Capítulo 17 trata sobre los musicales en escena. Romera Castillo también ha incursionado en este terreno de estudio y nos ofrece una muestra de carteles -con sus referencias en la red-, títulos de obras, elencos, tramas, así como datos sobre las producciones y sobre la presencia del Stage Entertainement España para montar obras como Los miserables, El rey león o Cabaret. El capítulo se cierra con una reflexión acerca del factor financiero en la puesta en escena de este tipo de espectáculos.

"Apostillas teatrales" es el título de la parte final de este dilatado viaje por la pluralidad de las manifestaciones escénicas exploradas por Romera Castillo. Aquí hace un breve pero sustancioso recorrido por el significado del término "autor", a partir del teatro áureo español. Señala que es indudable que el autor del texto literario teatral pertenece a la historia literaria, puesto que "las obras de cualquier dramaturgo pueden ser leídas como una novela o un poema" (424). No obstante, hace notar que el proceso de comunicación es completamente diferente al literario cuando un texto es llevado a la escena: la semiótica ha establecido que el lenguaje verbal se acompaña de otros tipos de lenguajes

4 Los trabajos dieron lugar a dos libros: Romera Castillo, José, editor. Erotismo y teatro en la primera década del siglo XXI. Madrid: Visor Libros, 2012; y Romera Castillo, José, editor. Teatro y marginalismo(s) por sexo, raza e ideología en los inicios del siglo. Madrid: Verbum, 2017. 
INVESTIGACIÓNTEATRAL

Revista de artes escénicas y performatividad

Vol. 12, Núm. 19

abril-septiembre 2021
Teatro de ayer y hoy a escena,

de José Romera Castillo

Raquel Graciela Gutiérrez Estupiñán

no verbales; lo que le otorga características significantes específicas y determina su plurifuncionalidad.

La plétora de datos contenidos en este libro conforma un mosaico sumamente variado. Se trata de un hito relevante en la trayectoria de José Romera Castillo, quien nos ofrece una obra de indudable utilidad para consulta, búsqueda bibliográfica y localización de trabajos, tanto en libros y revistas como a través de la red. 